\title{
Teaching Exploration and Practice on Classification Training of the Course Principle of Metal Plastic Forming
}

\author{
Chuanjie Wang ${ }^{1, a}$, Dong Luan ${ }^{1, b}$ and Peng Zhang ${ }^{1, c}$ \\ ${ }^{1}$ School of Materials Science and Engineering, Harbin Institute of Technology at Weihai, Weihai \\ 264209, China. \\ acjwang@hitwh.edu.cn, ${ }^{\mathrm{b}} \mathrm{mse} \_$luan@yeah.net, ${ }^{\mathrm{c}}$ pzhang@hit.edu.cn
}

Keywords: Principle of metal plastic forming, classification training, teaching reform.

\begin{abstract}
In the view of the course of principle of metal plastic forming with a strong theoretical and practical features, combining with the training objectives of the specialty of material forming and controlling engineering, this study carries on the exploration and practice to the reformation of course teaching in teaching content, teaching methods and other aspects by starting with the cultivation of students' classification, with the goal of enhancing the student's ability of combining theory and practice.
\end{abstract}

\section{Introduction}

The specialty of material forming and controlling engineering is on the background of advanced manufacturing industry and aims to strengthen the cross penetration of materials science and engineering, computer simulation technology and advanced manufacturing technology and other disciplines. At present, the setup of the courses of material forming and controlling engineering is mainly with the thinking of "wide caliber, easy employment". The range classes of related courses opened is wider and wider, the class hour is compressed less and less. The arrangement basically assures the employment rate and the postgraduate entrance examination rate of the undergraduate students, but it causes a great contradiction of the teaching content and the teaching time of each course, which seriously affects the improvement of teaching quality. The course of principle of metal plastic forming is a compulsory basic theory courses for students of the subject, insufficient class hour not only affects the teaching quality of the related professional courses,such as plastic deformation technology, material forming equipment, rolling mill practice, die casting technology, special plastic forming technology, etc., but also the students' professional theoretical level. They are not able to improve the production process and develop new technology and so on. Besides, it is found that in the process of teaching in recent years, most of the students still have some status that they don't understand the purpose and content, the depth of theory and application of the course, etc. At present, the students only complete the existing syllabus task, it is still not enough for the students that take up jobs to apply the theory to the process of production.

Principle of metal plastic forming involves the knowledge points of material type, the processing principle and elastic-plastic mechanics. There are many complicated contents and concepts. It also needs to integrate development and production process of material research into the teaching process and keeps the contents always be basic, advanced and application. Combined with course teaching practice of principle of metal plastic forming in our school, the authors make a preliminary exploration in terms of teaching reform of classification training. The authors also propose some concrete reform measures in the teaching content, teaching methods, teaching means and practice teaching, and strive to improve the teaching quality and effect of the course classification.

\section{Teaching classification for students}

The speciality of material forming and controlling engineering enrolls 90 students every year in our school. In recent years, the number of students that employed accounted for about $60 \%$ and the number of students that continued to study accounted for about $40 \%$. The students employed are 
mainly engaged in the work field of machinery, automobiles and materials industries. Most of them are working in the enterprise or technology research and development center in institute. The work needs them to have a high technology practice. The students for further study are mainly working in the material processing engineering disciplines for academic master's degree or applied master's degree. A higher level of professional theory is needed for the students to obtain the diploma. The teaching reform of the personnel training modes in material forming and controlling engineering from wide caliber cultivation to classified cultivation is imperative.

The course of principle of metal plastic forming is a basic course for the students in the specialty of material forming and controlling engineering. The course is open to the third grade students and the course enables students to understand and master kinds of the common basis and laws of plastic processing methods. The course also enables students to improve the ability to analyze and solve the practical problems of plastic processing. The necessary foundation for learning the follow-up professional courses and engaging in plastic processing work is by the learning the course. If we still follow the traditional teaching mode, it is difficult to achieve the goal of classified cultivation. We must put forward a set of classified training program for the teaching content system and teaching methods.

\section{System optimization of teaching content}

The course of principle of metal plastic forming in China has been open for many years, and many related textbooks also have been published. There are many teaching contents, including stress analysis, strain analysis, relationship between stress and strain, yield criterion, the plastic deformation mechanism, the main stress analysis method, the slip line field theory and its application, work balance method, upper bound method, finite element method and so on. Theoretical derivation and mathematical calculation, space coordinate transformation in the deformation process, change of material properties of the plastic deformation process and other key contents involved in the curriculum teaching process are complex. How to make students master the basic knowledge, understand the solving methods and apply in the processes in limited time is a difficult course.

On the basis of summing up the past teaching experience and combining with the situation of students, the course contents are updated, decomposed, adjusted and restructured timely. Then three levels of theoretical teaching content system are set up as followings:

Basic class hours: strengthening the concept and ensuring the foundation. It is to make sure that the students lay a solid foundation of the theoretical knowledge of material processing. The part of basic class hours occupies $50 \%$ of the total class hours. The teaching contents mainly are mechanical foundation and basic theories of the plastic forming. It is easier to make the students understand the contexts of the basic theoretical knowledges and their distribution in the chapter by using the topological graph. For example, in the teaching process of the stress analysis, the unidirectional stress state - plane stress state - the three-dimensional stress state, normal stress, shear stress, principal stress, principle shear stress and stress tensor, are taught step by step. Then finally we summer up the topological relations of stress analysis section. The students need to preview teaching content of strain analysis and summer up the topological relations of strain analysis section after-school by themselves.

Improve class hours: contents selected carefully and updated continuously. The professional course contents with systematic theoretical and strong practicability are selected for the professional direction to meet the needs of professional development. The improveclass hours account for $30 \%$ of the total class hours. The main teaching contents are the basic application of plastic forming theory. For example, the practical application of yield criterion in the plastic processing, how to choose the appropriate yield criterion correctly to analyze the deformation force theory, how to control deformation to occur in required parts according to the yield criterion, and how to control deformation force by making full use of the friction force, etc.

Special class hours: pioneering thinking and practical innovation. A new method to analyze and design the principle of material forming is selected for introducing the principle of the new 
technology to train students' ability of design and development. The class hours of special topics account for $20 \%$ of the total class hours. The teaching contents are mainly the frontier theory, scientific research achievements. For example, the related basic theories, the applicability and implementation process of the finite element software are taught by showing students the finite element simulation animation process of spinning. It is also needed to guide the students to submit process case report by extended homework after class.

\section{Reasonable arrangement of teaching methods}

The teaching method has been reformed while the optimization of the teaching content system has achieved initial success At the same time.It is urgent to attracte the students' initiative by the special way of teaching methods, because there are a wide range of equations and abstract contents. It is necessary to adopt the teaching mode "strengthening theory, hands-on practice and design innovation" on the basis of the matching with teaching content system.

Firstly, the organic combination of multimedia and blackboard writing. The content of the teaching knowledge is first displayed by multimedia during the course of teaching, so that students can understand the overall context of a point of knowledge. Derivation of formulas is carried out on the blackboard to make students master the whole derivation process and mathematical methods used. Before studying this course, the students have studied the basic courses, such as advanced mathematics, mechanics of materials, etc. For the analytic method that students have been mastered, teachers adopt the teaching mode that they guide the whole process and ask students the process details. For example, the limit, integral, derivative and variation principle in advanced mathematics have been used to solve problems in plastic mechanics. It is not only benefit to review the contents of the study, but also increase the students' interest in the course by asking the students the parsing detail.

Secondly, formula are processed graphically. The students must understand the significance of the expression deeply because the derivation of formulas in the course is complex. It is conscious to guide the students to imagine and draw the space of the derived formula during the teaching course. For example, the students are asked to draw the graphics in the coordinate system after the deduction of expression of the relationships between the normal stress and the shear stress in the plane stress state and the three-dimensional stress state, the normal stress and the shear stress. During the graphical formula teaching process, it is not only enable the students to understand the changes of coordinates in the plastic deformation process, but also master the drawing methods for spatial graphs by Matlab, Origin, Excel and other software tools.

Thirdly, the concept of innovation penetrating in the theoretical link. For the training process of engineering students, teachers not only teach professional theoretical knowledge to promote their ability to solve problems, but also train their innovative ability. Principle of metal plastic forming is a basic course for the specialty of material forming and controlling engineering, which provides the direct theoretical basis for the following courses and practical courses. We not only make students think that the course is just a method which can solve problems, but also make them understand and apply the basic knowledge to expand new materials and new technology. For example, teachers guide students to classify material forming processes and define the application range of material through the theory of the yield criterion during teaching the theory and application of yield criterion. Teachers also guide the students to reduce the deformation force by using which measures, when teach students how to analyze the deformation force by the principal stress method and the finite element method. These ways can make them have the concept of plastic deformation process optimization design initially, and lay the foundation for the teaching of the follow-up courses and the understanding of the professional curriculum system.

Many theories in principle of metal plastic forming are abstract. Students can understand deeply and achieve mastery only through the practice of the practical engineering problems. The experimental teaching content system with "three levels" is setup in the experimental teaching process: 
Basic experiment (must do): combine with the teaching contents of the course closely, complete the prescriptive required experiments, master the usage and operating skills of basic instruments. Take the upsetting experiment for an example, the aim is to make students master operating skills of the press, machining methods of blanks, the changes of stress and strain in the upsetting, deformation force calculation by the main stress method, experimental results verification and so on.

Design and research (optional): set up a comprehensive elective experiment for the students who have learning capacity, the strong interest, research and handing ability. Take rolling experiment for example, the aim is to make students master the changes of stress and strain in the rolling process, the flow characteristics of material in the deformation zone, drawing stress state distribution diagram, etc.

Development and production (optional): great importance to the special talents. Providing fully convenience and cultivating specially to the top students who have researching ability and creativity to make them have the ability to develop new technology initially. Take the repeating extrusion test for example, the aim is to make the students understand the changes of stress and strain and the flow characteristics of material in the process, how to design cyclical extrusion ratio and how to control structure property of material, etc.

\section{Conclusions}

The course of principle of metal plastic forming in our school has been opened for many years, the students generally inform that the learning efficiency is very well after the reform and practice in recent years. And the employment units also deem that the graduates have solid theoretical basis and strong engineering practice ability. To adapt the new situation of domestic and foreign materials industry development and the urgent need of the cultivation of material forming technology talents, the teaching reform of the course of principle of metal plastic forming will go on all the way, and also it is a long-term task.

\section{Acknowledgments}

The corresponding author Peng Zhang on behalf of all the authors of the paper gratefully acknowledges the financial support of the Graduate Educational Reform Project of Harbin Institute of Technology (No. JGYJ-201652) and Graduate Educational Innovation Project of Shandong Province (No. sdyy11001).

\section{References}

[1] G.Y. Lin, L.B. Yang, M.G. Chen, D.S. Peng. The reform and practice of the teaching of the course of Elastic Plastic Mechanics, J. Soc. Sci. Hunan Med. 8(2006) 205-207.

[2] Z.R. Wang, Fundamentals of Elasticity and Plasticity, Harbin Institute of Technology Press, Harbin, 1997.

[3] H.Q. Yu, Principles of Metal Forming, China Machine Press, Beijing, 2010.

[4] D.S. Peng, Principle of Plastic Deformation in Metals Processing, Central South University Press, Changsha, 2004. 